\title{
Functional Connectome of the Striatal Medium Spiny Neuron
}

\author{
Nao Chuhma, ${ }^{1,3 *}$ Kenji F. Tanaka, ${ }^{2,5 *}$ René Hen, ${ }^{2,4}$ and Stephen Rayport ${ }^{1,3}$ \\ Departments of ${ }^{1}$ Psychiatry and ${ }^{2}$ Pharmacology, Columbia University, New York, New York 10032, Departments of ${ }^{3}$ Molecular Therapeutics and \\ ${ }^{4}$ Integrative Neuroscience, New York State Psychiatric Institute, New York, New York 10032, and ${ }^{5}$ Division of Neurobiology and Bioinformatics, \\ National Institute for Physiological Sciences, Okazaki, Aichi 444-8787, Japan
}

Dopamine system disorders ranging from movement disorders to addiction and schizophrenia involve striatal medium spiny neurons (MSNs), yet their functional connectivity has been difficult to determine comprehensively. We generated a mouse with conditional channelrhodopsin-2 expression restricted to medium spiny neurons and assessed the specificity and strength of their intrinsic connections in the striatum and their projections to the globus pallidus and the substantia nigra. In the striatum, medium spiny neurons connected with other MSNs and tonically active cholinergic interneurons, but not with fast-spiking GABA interneurons. In the globus pallidus, medium spiny neurons connected strongly with one class of electrophysiologically identified neurons, but weakly with the other. In the substantia nigra, medium spiny neurons connected strongly with GABA, but not with dopamine neurons. Projections to the globus pallidus showed solely D2-mediated presynaptic inhibition, whereas projections to the substantia nigra showed solely D1-mediated presynaptic facilitation. This optogenetic approach defines the functional connectome of the striatal medium spiny neuron.

\section{Introduction}

Neural circuits are determined by their connections. However, what we know about neuronal connectivity is based on anatomical studies that provide a rich matrix of wiring information, but little information on the strength of connections (Bohland et al., 2009). Physiological studies of connectivity have been limited by the inability to stimulate identified cell populations. Recently, optogenetics has provided the means to activate genetically targeted neurons (Boyden et al., 2005; Zhang et al., 2006; Arenkiel et al., 2007; Kuhlman and Huang, 2008). Current optogenetic approaches, however, drive channelrhodopsin-2 (ChR2) expression with either a strong promoter such as Thyl (Arenkiel et al., 2007), which does not drive expression in a well defined population of cells, or with virus injections, which even if genetically restricted (Kuhlman and Huang, 2008; Tsai et al., 2009) do not provide consistent expression across injected animals. Neither of these approaches provides access to defined populations of neurons with the consistent expression requisite for the quantitative assessment of the specificity and strength of their connections. These issues would be obviated in transgenic mice with cell typespecific promoters driving ChR2 expression.

\footnotetext{
Received July 23, 2010; revised 0ct. 12, 2010; accepted Nov. 9, 2010.

This work was supported by National Institute on Drug Abuse Grant DA017978 (S.R.), National Alliance for Research on Schizophrenia and Depression and National Institute of Natural Sciences Laser Biology Project (K.F.T.), National Institute of Mental Health Grant MH068542, New York State Stem Cell Science (R.H.), and the Lieber Center for Schizophrenia Research and Treatment at Columbia University (S.R., N.C.). We thank Karl Deisseroth for the ChR2-mCherry fusion CDNA, Edward Boyden for the Halo-EGFP fusion CDNA, Hermann Bujard for the Bi-tet0 promoter CDNA, and Kohsuke Yusa for the pMCS plasmid. We thank Shouta Sugio for help with immunohistochemistry. *N.C. and K.F.T. contributed equally to this work.

Correspondence should be addressed to Stephen Rayport, Columbia University, New York State Psychiatric Institute Unit 62, 1051 Riverside Drive, New York, NY 10032. E-mail: sgr1@columbia.edu.

DOI:10.1523/JNEUROSCI.3833-10.2011

Copyright $\odot 2011$ the authors $\quad 0270-6474 / 11 / 311183-10 \$ 15.00 / 0$
}

Elucidating the functional connectivity of striatal medium spiny neurons (MSNs) is of compelling importance because of their pivotal role in motor control, habit formation, and motivated behavior (Graybiel et al., 1994; Yin and Knowlton, 2006), as well as their altered function in major neuropsychiatric disorders ranging from Parkinson's disease and Huntington's disease to schizophrenia and addiction (Graybiel, 2000; Kreitzer and Malenka, 2008; Robbins et al., 2008; Simpson et al., 2010). How they are interconnected in the striatum (Str) has only been determined recently (Taverna et al., 2008), and how they connect with other Str neurons has been barely addressed. While their major projections to the globus pallidus (GP), making up the indirect pathway, and to the substantia nigra (SN), making up the direct pathway, are well known (Wilson, 2004), relatively little is known about the identity of their postsynaptic partners or the specificity and strength of their connections.

To address the broader issue of functional connectivity and more specifically the MSN functional connectome, we have made novel transgenic mice expressing ChR2 under the control of the tetO promoter and bred them with $\alpha$ CaMKII-tTA mice to achieve selective expression of ChR2 in striatal MSNs. In these mice, ChR2 is expressed in a Golgi-like manner in a subset of MSNs, without apparent bias to MSN subtypes or striatal subregions. We have determined the cell type specificity and strength of MSN connections comprehensively and addressed several abiding issues concerning their connectivity.

\section{Materials and Methods}

Bigenic BTR:: $\alpha$ CaMKII-tTA mice. Mice were handled in accordance with the guidelines of the National Institutes of Health Guide for the Care and Use of Laboratory Animals, under protocols approved by the Institutional Animal Care and Use Committees of Columbia University (New York, 
NY), New York State Psychiatric Institute (New York, NY) and the National Institute of Physiological Sciences (Okazaki, Japan).

We used the tetracycline transactivator (tTA)-tetracycline operator (tetO) promoter strategy (Gossen et al., 1995) to drive cell type-specific expression of ChR2 in MSNs of the striatum. In this strategy, two lines of mice are bred, one with cell type-specific promoter driving tTA expression, and the other with the tetO promoter driving the desired transgene. When tTA binds to tetO, the transgene is induced. While transgene induction can be turned off by administration of doxycycline (which could be used to rule out toxicity issues associated with transgene expression), we used the system solely to achieve cell type specificity. We bred $\alpha$ CaMKII-tTA mice (Mayford et al., 1996) with newly developed transgenic bidirectional tetO-rhodopsin (BTR) mice. Although $\alpha$ CaMKII promoter-driven tTA is widely expressed in the forebrain, tTA-mediated transgene induction restricted to the Str has been reported in $\sim 20 \%$ of crosses with tetO lines (Mayford et al., 1996), most recently in crosses with tetO-D2 dopamine (DA) receptor mice (Kellendonk et al., 2006).

To generate the BTR mice, we sequentially ligated, in the multicloning site of the pMCS plasmid (gift from Kosuke Yusa, Osaka University, Osaka, Japan), the SV40 polyadenylation signal ( $0.2 \mathrm{~kb}$, reverse orientation), halorhodopsin-enhance green fluorescent protein (EGFP) fusion cDNA fragment $(1.6 \mathrm{~kb}$, reverse orientation, gift from Edward Boyden, Massachusetts Institute of Technology, Cambridge, MA), bidirectional tetO promoter $(0.6 \mathrm{~kb}$, gift from Hermann Bujard, University of Heidelberg, Heidelberg, Germany), ChR2-mCherry fusion cDNA (1.7 kb, gift from Karl Deisseroth, Stanford University, Stanford, CA), and SV40 polyadenylation signal $(0.2 \mathrm{~kb})$, as schematized in Figure $1 \mathrm{~A}$. The $3.4 \mathrm{~kb}$ construct was injected into fertilized eggs of CBA/C57BL/6 mice. The following PCR primer sets were used for mouse genotyping: EGFP1 (5'-AAATTCAGGAAGCTGTGTGCCTGC-3') and EGFP2 (5'-CGGAGTTGATCACCTTGGACTTGT-3') for BTR mice, and NNU (5'-AGGCTTGAGATCTGGCCATAC-3') and XZTL (5'-AAGGGCAAAAGTGAGTATGGTG-3') for CaMKII-tTA mice.

We obtained three founder lines (BTR3, 6, and 7), which we mated with $\alpha$ CaMKII-tTA mice, line B. Only BTR6 progeny showed ChR2mCherry expression and thus were used for experiments. BTR6 and their bigenic progeny were healthy, did not show abnormal posture or movement, and reproduced normally over their lifespan.

Imaging fused fluorescent proteins and immunohistochemistry. Mice (aged P28-P56, where P is postnatal day) were anesthetized with sodium pentobarbital and perfused with $20 \mathrm{ml}$ of $4 \%$ paraformaldehyde (intracardiac route). Sagittal brain sections, $100 \mu \mathrm{m}$ thick, were cut using a vibratome (DTK-3000, Dosaka), and mounted in glycerol/PBS. Confocal images were captured with a laser-scanning LSM510 microscope (Zeiss), and epifluorescent images at low magnification were captured with a dissection microscope equipped with DP70 CCD camera (Olympus). For imaging acute slices, sagittal brain slices were cut $400 \mu \mathrm{m}$ thick with a VT1200S vibrating microtome (Leica). Fluorescent images were captured with a Sensys chilled CCD camera (Roper Scientific) on an upright fluorescence microscope (BX61WI, Olympus) with $4 \times$ air or $60 \times$ water immersion lenses.

For assessment of the distribution of tTA, $\alpha$ CaMKII-tTA were bred with tetO-mCherry reporter mice (K. Tanaka, manuscript in preparation) and processed for immunohistochemistry. Floating sections were incubated with primary antibodies overnight at room temperature. The following antibodies were used: anti-red fluorescent protein (rabbit polyclonal, 1:1000 dilution, Clontech), anti-parvalbumin (mouse monoclonal, clone 235, 1:5000, Swant), and anti-DARPP32 (mouse monoclonal, clone 15/DARPP-32, 1:250, BD Biosciences). After two washes with PBS, sections were incubated with Alexa 568- and Alexa 488-tagged secondary antibodies (Invitrogen) for $2 \mathrm{~h}$. Confocal epifluorescence images were captured (LSM510, Zeiss).

ChR2 expression in the patch and matrix Str subregions was assessed by double immunocytochemistry. BTR:: $\alpha$ CaMKII-tTA mice were perfused with $4 \%$ paraformaldehyde and their brains removed, postfixed overnight in the same fixative, cryoprotected in PBS containing 20\% sucrose overnight, and frozen in methylbutane cooled on dry ice, and sections $(35 \mu \mathrm{m})$ were cut on a CM-3050S cryostat (Leica). Sections (floating) were incubated with anti-red fluorescent protein (rat monoclonal, 1:500, ChromoTek) and anti-mu opioid receptor (rabbit polyclonal, 1:5000, Abcam) antibodies overnight, followed by a $2 \mathrm{~h}$ incubation with biotinylated anti-rat and anti-rabbit biotinylated secondary antibodies, and visualized with a Vectastain Elite $\mathrm{ABC}$ kit using $\mathrm{DAB}$ as the chromogen (Vector Laboratories).

Brain slice preparation for recording. For brain slice recordings, bigenic $\alpha$ CaMKII-tTA::BTR6 mice (P30-P65) were anesthetized with ketamine/ xylazine i.p. Brains were removed to ice-cold, high-glucose artificial CSF (ACSF) saturated with carbogen $\left(95 \% \mathrm{O}_{2} ; 5 \% \mathrm{CO}_{2}\right)$. The composition of the high-glucose ACSF was (in mM): $75 \mathrm{NaCl}, 2.5 \mathrm{KCl}, 26 \mathrm{NaHCO}_{3}, 1.25$ $\mathrm{NaH}_{2} \mathrm{PO}_{4}, 0.7 \mathrm{CaCl}_{2}, 2 \mathrm{MgCl}_{2}$, and 100 glucose, adjusted to $\mathrm{pH}$ 7.4. Coronal or horizontal slices, $400 \mu \mathrm{m}$ thick, were cut with a vibrating microtome (VT1200S). Slices were preincubated in high-glucose ACSF saturated with carbogen for $1 \mathrm{~h}$ at room temperature and then transferred to the recording chamber (submerged, $500 \mu \mathrm{l}$ volume) on the stage of a fluorescence microscope (BX61WI, Olympus) and visualized with a $60 \times$ water-immersion lens.

Photostimulation and electrophysiology. ChR2 expression was confirmed by mCherry expression, visualized with a Texas Red filter (XF102-2, excitation 533-587 nm, Omega Optical). ChR2 and HaloR responses were evoked by short pulses (1-100 ms duration, $0.1-5 \mathrm{~Hz}$ ) of blue light (GFP filter, U-MWIB, excitation 460-495 nm, Olympus) or yellow light (Texas Red filter) from a standard mercury arc lamp (100 W) controlled with a Uniblitz electronic shutter (Vincent Associates). Recorded neurons were visualized using enhanced visible light differential interference contrast optics with a CCD camera (OLY-150, Olympus). Recording patch pipettes were fabricated from borosilicate glass capillary with filament (standard wall thickness; World Precision Instruments). Pipette resistance was 3-5 M $\Omega$. Composition of standard intracellular solution was (in mM): $140 \mathrm{~K}^{+}$-gluconate, $10 \mathrm{HEPES}, 0.1 \mathrm{CaCl}_{2}, 2 \mathrm{MgCl}_{2}$, 1 EGTA, 2 ATP-Na , and 0.1 GTP-Na, pH 7.3. To block action current or potentials, the $\mathrm{Na}^{+}$channel blocker lidocaine $N$-ethyl bromide $(5 \mathrm{mM}$, QX-314, Sigma-Aldrich) was added to the intracellular solutions. $\mathrm{GABA}_{\mathrm{A}}$ synaptic responses were recorded with a high $\mathrm{Cl}^{-}$intracellular solution to flip and enhance the IPSCs to enhance detection. The composition of the high $\mathrm{Cl}^{-}$intracellular solution was (in mM): 140 $\mathrm{KCl}, 2 \mathrm{MgCl}_{2}, 10$ HEPES, 1 EGTA, 2 ATP-Na $\mathrm{Na}_{2}$ and 0.2 GTP-Na $2, \mathrm{pH}$ 7.3. For pharmacological studies, $\mathrm{KCl}$ was replaced by $\mathrm{CsCl}$ to improve space clamp and QX314 was added to block spontaneous firing. The recording chamber was continuously perfused $(1.5 \mathrm{ml} / \mathrm{min})$ with standard ACSF (in mM): $125 \mathrm{NaCl}, 2.5 \mathrm{KCl}, 25 \mathrm{NaHCO}_{3}, 1.25$ $\mathrm{NaH}_{2} \mathrm{PO}_{4}, 2 \mathrm{CaCl}_{2}, 1 \mathrm{MgCl}_{2}$, and 25 glucose, $\mathrm{pH} 7.4$, saturated with carbogen. Recordings were done at $32-33^{\circ} \mathrm{C}$ (TC $344 \mathrm{~B}$ temperature controller, Warner Instruments).

Both voltage and current-clamp recordings were performed using an Axopatch 200B (Molecular Devices). Holding potential was $-80 \mathrm{mV}$ for recording ChR2/halorhodopsin (HaloR) responses in MSNs and -60 $\mathrm{mV}$ for synaptic responses, unless noted otherwise. Current-clamp recordings were done in fast current-clamp mode. Series resistance (10-35 $\mathrm{M} \Omega$ ) was compensated online by $70-80 \%$. Liquid junction potential

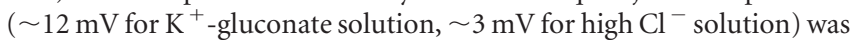
adjusted online. To allow for diffusion of intracellular solution within recorded cells, data acquisition commenced 5 min after achieving wholecell mode. For determining the properties of recorded neurons, 200-400 pA hyperpolarizing or depolarizing step currents (700 ms duration) were injected through the recording pipette under current-clamp. For pharmacological study, gabazine (SR95531, Tocris Bioscience), 6-cyano-7nitroquinoxaline-2,3-dione (CNQX, Sigma-Aldrich), SKF83822 (Tocris Bioscience), SCH23390 (Sigma-Aldrich), (-)-quinpirole (Tocris Bioscience), or sulpiride (Tocris Bioscience) were added by perfusion. Drugs showed an initial effect within $2 \mathrm{~min}$ and their full effect within 4 min.

Data acquisition and analysis. Electrophysiological recordings were filtered at $5 \mathrm{kHz}$ using a four-pole Bessel filter and digitized (ITC-18 Interface, ALA Scientific Instruments) at $100 \mu$ s intervals for determination of membrane properties and at $200 \mu$ s intervals for ChR2/HaloR and synaptic responses. Acquisition and analysis was done using Pulse Control 4.7 (Richard J. Bookman, University of Miami, Miami, FL) running 

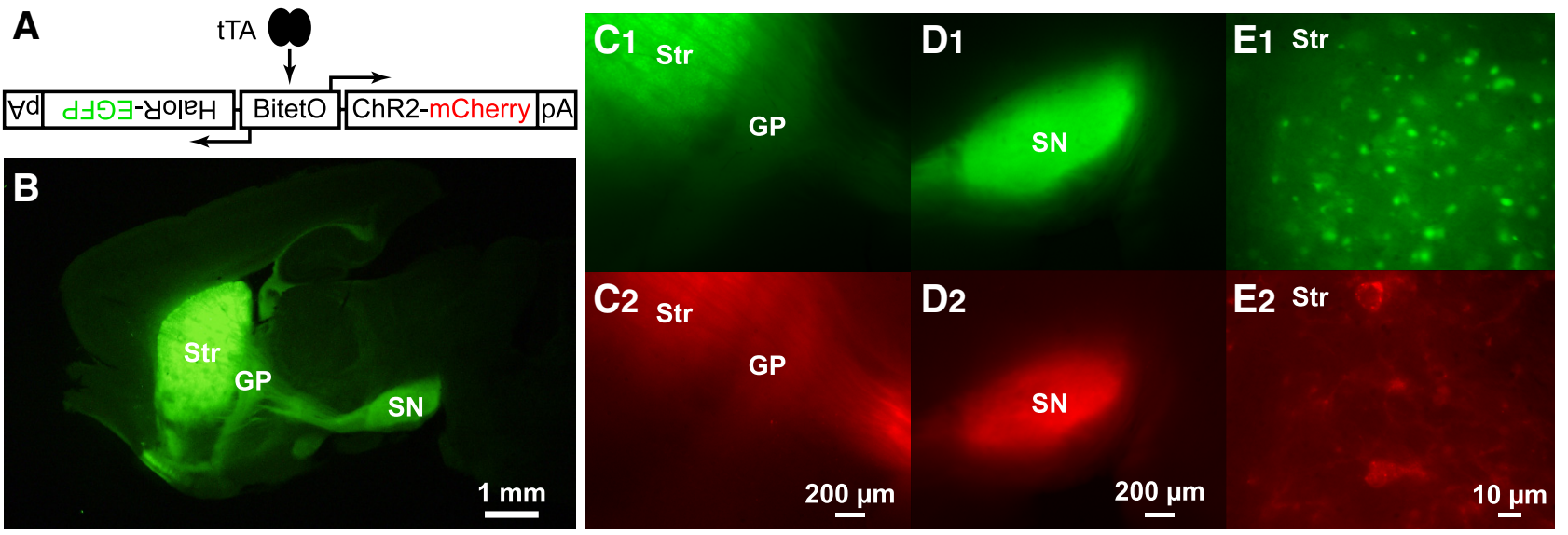

Figure 1. BTR:: $\alpha$ CaMKII-tTA bigenic mouse. $A$, Strategy for induction of bidirectional gene expression of ChR2 tagged with mCherry and HaloR tagged with EGFP under tetracycline transactivator (tTA) control. Bitet0, Bidirectional tetracycline promoter; pA, polyadenylation signal. BTR mice were bred with $\alpha$ CaMKII-tTA mice to confer Str-specific expression. $\boldsymbol{B}$, EGFP epifluorescence in BTR::: $\alpha$ CaMKII-tTA bigenic mice at low magnification in a fixed $100 \mu \mathrm{m}$ sagittal section. EGFP fluorescence revealed expression in the dorsal Str and the projections. $\boldsymbol{C}-\boldsymbol{E}$, Epifluorescence of EGFP and

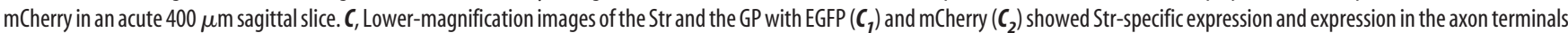
of MSNs in the GP. $\boldsymbol{D}$, Lower-magnification images of the SN with EGFP $\left(\boldsymbol{D}_{\boldsymbol{1}}\right)$ and mCherry $\left(\boldsymbol{D}_{2}\right)$ showed expression in the axon terminals of MSNs in the SN. $\boldsymbol{E}$, High-magnification images of EGFP in the Str showed many small puncta, presumably HaloR aggresomes $\left(\boldsymbol{E}_{1}\right)$. In contrast, mCherry fluorescence $\left(\boldsymbol{E}_{2}\right)$ was seen in fewer but clearly identifiable cells, revealing ChR2 in the plasma membrane.

under Igor Pro 4.04 (WaveMetrics) or Axograph X (Axograph Scientific), running on a PowerMac G4 (Apple). Synaptic response traces were filtered digitally at $2 \mathrm{kHz}$ to remove shutter noise. The amplitude of ChR2/Halo or synaptic responses was evaluated by measuring peak amplitude from averages of 10 consecutive responses.

To determine whether there were connections, we measured $0.2 \mathrm{~s}$ of the baseline from each cell and calculated the mean +2 SD using Axograph X. Spontaneous synaptic activity was not blocked and included in the baseline determination. Responses exceeding the mean +2 SD level were counted as connections. Statistical analyses were done in Statview 5.01 (SAS Institute) or SPSS 17 (SPSS). Data are reported as mean \pm SEM unless otherwise noted.

\section{Results}

BTR:: $\alpha$ CaMKII-tTA bigenic mice with restricted ChR2 expression in striatal MSNs

We generated transgenic mice with a bidirectional tetO promoter driving ChR2-mCherry on one allele and HaloR-EGFP on the other, with the goal of achieving bidirectional control of neuronal excitability. These BTR mice (Fig. 1A) were bred with a line of $\alpha$ CaMKII-tTA mice (Mayford et al., 1996) with striatal tTA expression restricted to MSNs (Kellendonk et al., 2006). Bigenic BTR:: $\alpha$ CaMKII-tTA mice showed specific expression of EGFP and mCherry in the dorsal Str and projections to the GP and the $\mathrm{SN}$ (Fig. $1 B-E$ ). Labeling did not, however, extend into the ventral Str; there was little fluorescence in the nucleus accumbens (Fig. $1 B$ ).

Within the dorsal Str, labeled MSNs were randomly distributed, without apparent regard for the patch/matrix organization of the Str. EGFP (tag for HaloR) expression was stronger than that of mCherry (tag for ChR2), both in the cell body (Fig. 1C, Str) and projection areas (Fig. $1 C, D$ ). However, higher resolution imaging revealed that EGFP accumulated in aggresomes in MSN cell bodies and was not seen in the plasma membrane. In contrast, mCherry fluorescence was seen in the membrane, outlining the cell soma, and extended into the processes (Fig. $1 \mathrm{E}$; supplemental Fig. S1, available at www.jneurosci.org as supplemental material). This suggested that ChR2, but not HaloR, would be functional.

To confirm that expression of ChR2 was specific to MSNs, we examined tTA transactivation in $\alpha$ CaMKII-tTA
mice::tetO-mCherry reporter mice (supplemental Fig. S2 A, available at www.jneurosci.org as supplemental material). tTA expression (mCherry fluorescence) overlapped completely with the MSN marker DARPP-32 (supplemental Fig. S2 B) but not with the fastspiking interneuron (FSI) marker parvalbumin (supplemental Fig. $\mathrm{S} 2 \mathrm{C}$ ). tTA was not expressed in cholinergic interneurons, which were discerned by their larger size, and that was consistent with previous observations in this $\alpha$ CaMKII-tTA line (Drew et al., 2007). Thus, in BTR:: $\alpha$ CaMKII-tTA bigenic mice, ChR2 expression was restricted to a subset of striatal MSNs.

Whereas yellow epifluorescence field illumination of EGFPexpressing MSNs barely elicited a HaloR response (supplemental Fig. S3), blue epifluorescence field illumination of mCherryexpressing MSNs elicited a large ChR2 response. In whole-cell recordings, we observed large inward currents under voltage clamp (Fig. $2 A_{1}$ ) and strong depolarizations under current clamp (Fig. $2 A_{2}$ ). The average peak amplitude of the evoked response was $30.5 \pm 4.1 \mathrm{mV}$ under current clamp $(n=13$ cells) and $346.3 \pm 66.6 \mathrm{pA}$ under voltage clamp (holding potential $-80 \mathrm{mV}, n=15$ cells). All mCherry-expressing neurons showed such excitatory responses. Responses were not affected by the $\mathrm{GABA}_{\mathrm{A}}$ antagonist gabazine (SR95531, $10 \mu \mathrm{M}$ ), nor the AMPA glutamate receptor antagonist CNQX $(40 \mu \mathrm{M})$, indicating that the responses were caused by direct activation of ChR2 and were not secondarily generated synaptic responses (Fig. 2B). ChR2 responses showed inward rectification at hyperpolarized holding potentials and a reversal potential of $\sim 0 \mathrm{mV}$ (Fig. $2 C$ ), the same current-voltage relationship observed in ChR2-transfected neurons in culture at physiological pH (Bamberg et al., 2008). ChR2 responses were reliably evoked with illumination longer than $2 \mathrm{~ms}$ and reached maximum amplitude with illumination longer than 5-10 ms (Fig. 2D). Depending on the frequency of photostimulation, the ChR2 response then reached a nadir, which diminished with increasing frequency (Fig. 2E).

\section{Connections of MSNs in the Str}

The majority of GABAergic terminals impinging on MSNs are thought to arise from neighboring MSNs (see calculations in Guzman et al., 2003). To assess these MSN-MSN connections, 
we recorded from non-mCherry (dark) MSNs (Fig. 1 E; supplemental Fig. S1). To enhance GABA responses, we used a $\mathrm{KCl}$ based intracellular solution $\left(E_{\mathrm{Cl}}\right.$ of $\left.\sim 0 \mathrm{mV}\right)$. As expected, MSNs were silent (Fig. $3 A_{2}$ ) and showed resting membrane potential of $-76.0 \pm 1.7 \mathrm{mV}$ ( $n=30$ cells $)$. With 200-300 pA depolarizing current injection, MSNs fired repetitive spikes with small after-hyperpolarizations (Fig. $3 A_{3}$ ). With repeated photostimulation $(10 \mathrm{~ms}$ at 0.1 $\mathrm{Hz}$ ), onset-locked, inward currents of varying amplitude were recorded under voltage clamp (holding potential -60 $\mathrm{mV}$ ) (Fig. $3 A_{4}$ ). These were completely blocked by the selective $\mathrm{GABA}_{\mathrm{A}}$ antagonist gabazine (SR95531, $10 \mu \mathrm{M}$ ) (Fig. $3 A_{5}$ ). We counted cells as receiving synaptic connections when evoked IPSCs exceeded the mean +2 SDs of the preceding baseline activity (including spontaneous synaptic responses). In MSNs, the mean +2 SD level of baseline activity was $3.2-12.3 \mathrm{pA}$. With this criterion, 19 of 30 recorded MSNs (63\%) showed synaptic connections. The average amplitude of the evoked IPSCs in cells with synaptic connections was $103.8 \pm 22.6$ pA $(n=19$ cells) (Fig. $3 B)$, whereas the average amplitude of the post-photostimulation epoch in cells without synaptic connections was $3.5 \pm 0.7 \mathrm{pA}(n=11$ cells) (Fig. 3B).

We then examined cholinergic and fast-spiking interneurons (FSIs), the two other major classes of Str interneurons. Cholinergic interneurons are at least twice the size of MSNs and thus readily distinguishable; they were never fluorescent and never showed direct responses to photostimulation. They had a resting membrane potential of $-60.7 \pm 1.3 \mathrm{mV}(n=$ 12 cells) and fired spontaneously, and thus are also known as tonically active neurons (TANs). Their spikes had large, slow after-hyperpolarizations (Kawaguchi, 1993) (Fig. $3 A_{2}, A_{3}$ ). Photostimulation evoked inward currents, smaller than those in MSNs (Fig. $3 A_{4}$ ), which were also completely blocked by gabazine (Fig. $3 A_{5}$ ). We found that 9 of 12 recorded cells $(75 \%)$ showed significant synaptic connections. The range of mean +2 SD level of baseline in TANs was $2.7-11.9 \mathrm{pA}$. The average amplitude of the evoked IPSCs in cells with synaptic connections was $16.9 \pm 2.9$ pA ( $n=9$ cells) (Fig. $3 B$ ), whereas the average amplitude of post-photostimulation epoch in cells without synaptic connections was $2.8 \pm 0.6 \mathrm{pA}(n=3$ cells) (Fig. $3 B)$.

Although FSIs are slightly larger than MSNs in rats (Kawaguchi, 1993), the size difference was not discernable in mice, so we identified FSIs based on their firing pattern; they were never fluorescent and never showed direct responses to photostimulation. We were unable to identify low-threshold spiking GABA interneurons, which constitute a very small subset $(1-2 \%)$ of striatal neurons (Kawaguchi et al., 1995). FSIs were not spontaneously

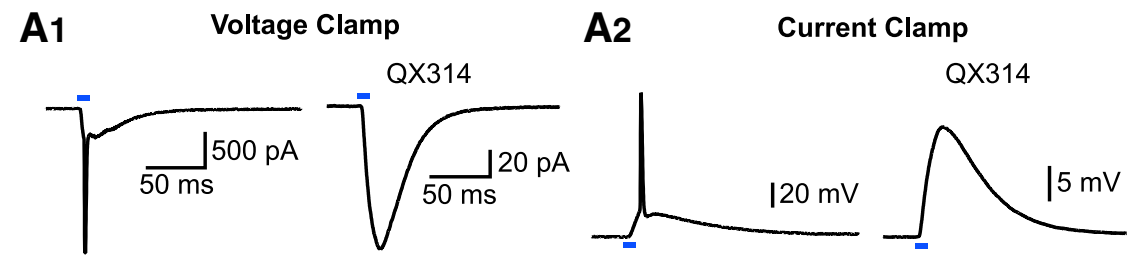

B

E1

D1

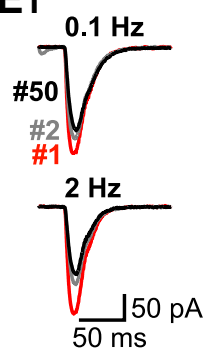

$\mathbf{C}_{1}$

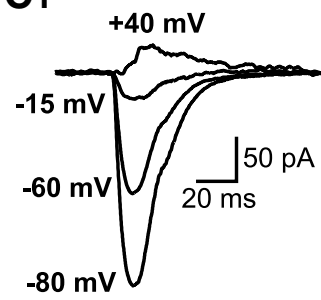

C2 Peak amp (ratio to $-80 \mathrm{mV}$ )

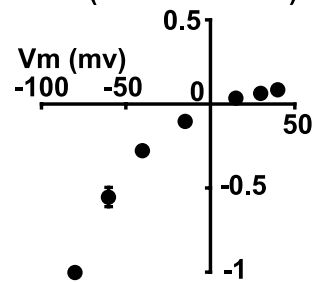

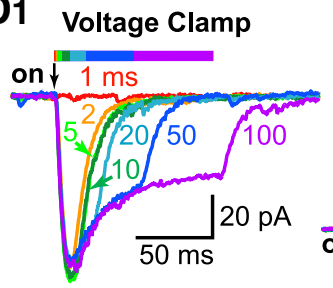

Current Clamp

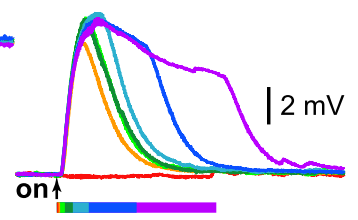

D2

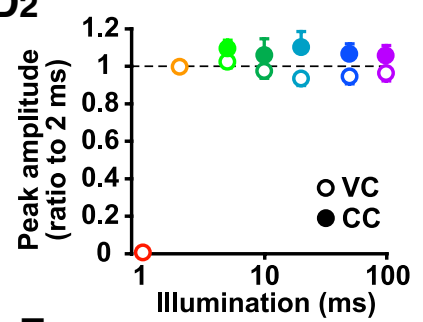

E2
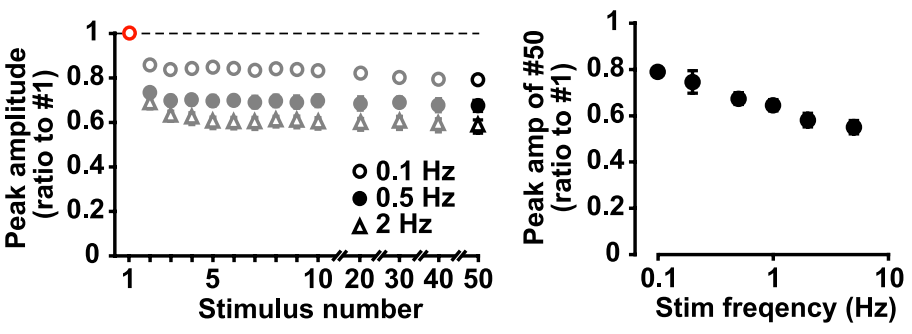

Figure 2. ChR2 excitation of mCherry MSNs. $\boldsymbol{A}$, ChR2 response in mCherry MSNs under voltage clamp $\left(\boldsymbol{A}_{\boldsymbol{1}}\right)$ and current clamp $\left(A_{2}\right)$. Excitation of ChR2 robustly activated mCherry MSNs (left traces); with intracellular QX314 to block Na ${ }^{+}$currents, the gabazine (10 $\mu \mathrm{m}$, red trace) or CNQX (40 $\mu \mathrm{m}$, orange trace). $\boldsymbol{C}$, Current-voltage relationship of the ChR2 response. $\boldsymbol{C}_{1}$, Sample traces of the $C h R 2$ responses at different membrane potentials. Averages of 10 traces are shown. $C_{2^{\prime}}$ Current-voltage relationship $00 \mathrm{~ms} . \boldsymbol{D}_{1}$, Typical responses recorded under voltage clamp (left) and current clamp (right). $\boldsymbol{D}_{2}$, Peak amplitude of the response tive to 2 ms illumination) under voltage clamp (open circles) and current clamp (closed circles) for each illumination duration; at $0.1 \mathrm{~Hz}$ (top) and $2 \mathrm{~Hz}$ (bottom) stimulation. $\boldsymbol{E}_{2}$, Peak amplitudes of ChR2 responses during 50 pulse stimulation at $0.1 \mathrm{~Hz}$ cells), $0.5 \mathrm{~Hz}$ (closed circles; $n=6$ cells) and $2 \mathrm{~Hz}$ (open triangles; $n=6$ cells). Amplitudes are expressed as the ratio of the initial response (red markers). $\boldsymbol{E}_{3}$, Reduction of peak amplitude of ChR2 response at the 50th stimulation. Data are shown as the ratio of the first pulse for each stimulus frequency; $n=6$ cells.

active, had a resting membrane potential of $-72.3 \pm 3.7 \mathrm{mV}(n=$ 6 cells), and, with depolarizing current injection, fired rapidly or in bursts. Their spikes had large, brief after-hyperpolarizations (Kawaguchi, 1993) (Fig. $3 A_{2}, A_{3}$ ). Photostimulation failed to evoke any apparent response $\left(n=6\right.$ cells) (Fig. $\left.3 A_{4}, A_{5}\right)$. The average of the post-photostimulation epoch was $3.2 \pm 0.7 \mathrm{pA}$ (Fig. $3 B$ ), which did not exceed the mean $+2 \mathrm{SD}$ level of the baseline (3.5-5.5 pA).

\section{Connections of MSNs in the GP}

MSNs are broadly divided into two classes distinguished by differential dopamine (DA) receptor expression: cotransmitter status and projection target (Wilson, 2004). D2 receptor-expressing MSNs make up the indirect pathway, use enkephalin as a cotrans- 
A
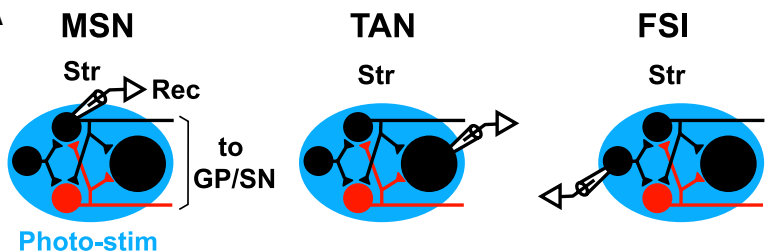

A2

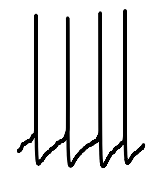

A3
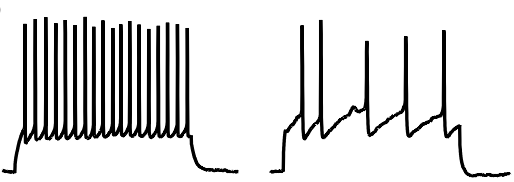

A4

A5
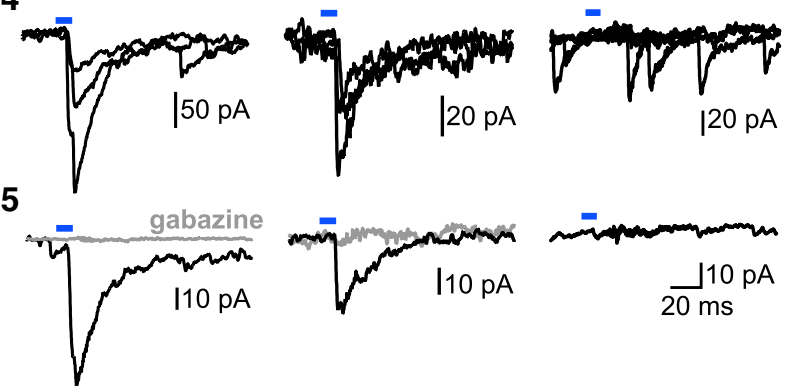

B

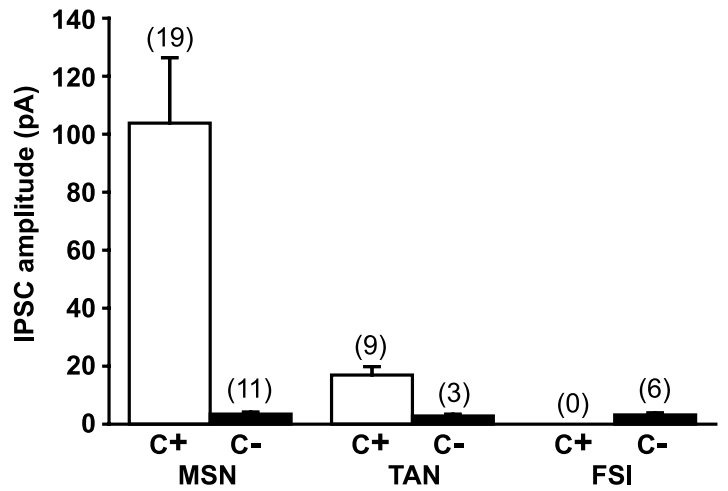

Figure 3. MSN connections in the Str. Light-evoked IPSCs in the dorsal Str from a non-mCherry (dark) MSN (left), TAN (middle) and FSI (right). $\boldsymbol{A}_{\boldsymbol{1}}$, Schematics of the Str circuitry with an electrode indicating the cell type recorded (Rec). mCherry MSNs expressing ChR2 are red. Non-mCherry MSNs with projection fibers, larger cells identified as TANs (which are the large cholinergic interneurons), and other interneurons without projection fibers, mainly FSIs, are in black. Blue ovals indicate the area of photostimulation (Photo-stim). $A_{2}, A_{3}$, Cell types were identified by their spontaneous firing pattern $\left(\boldsymbol{A}_{2}\right)$ and response to current injection $(200-300 \mathrm{pA})$ under current-clamp $\left(\boldsymbol{A}_{3}\right)$. TANs fired spontaneously $\left(\boldsymbol{A}_{2}\right.$, middle). $\boldsymbol{A}_{4}, \boldsymbol{A}_{5}$, Light-evoked IPSCs. Individual IPSC traces $\left(\boldsymbol{A}_{4}\right.$; three traces superimposed) and averages of 10 traces $\left(\boldsymbol{A}_{5}\right)$ are shown by cell type. Blue bars indicate timing of photostimulation (EGFP filter, $10 \mathrm{~ms}, 0.1 \mathrm{~Hz}$ ). Short illumination evoked synaptic responses in MSNs and TANs, which were completely blocked by gabazine (10 $\mu \mathrm{m}$; gray traces), while no apparent response was observed in FSIs. $\boldsymbol{B}$, Summary of the amplitudes of recorded light-evoked IPSC $s$ by cell type. Average amplitudes for cells with IPSCS $(C+$, with connection; open bars $)$ and average amplitudes from cells without significant IPSCS ( $C-$, no connection; closed bars) are shown. The number of cells recorded is shown in parentheses. No FSIs showed light-evoked IPSCS.

mitter, and project to the GP; D1 receptor-expressing MSNs make up the direct pathway, use substance $\mathrm{P}$ as a cotransmitter, and project to the SN. With electrical stimulation it has been very difficult to activate MSN terminals projecting to the GP selectively. While the majority of synaptic inputs to the GP are from
MSNs (Falls et al., 1983; Okoyama et al., 1987), there are significant GABAergic inputs from neighboring GP neurons (Okoyama et al., 1987; Kita and Kitai, 1994) that project back to the Str (Kita, 2007) so that electrical stimulation of the Str also activates pallidopallidal connections antidromically (Fig. $4 A_{1}$, schematic). However, in BTR:: $\alpha$ CaMKII-tTA mice, we could activate MSN inputs to the GP selectively.

In mice it was difficult to discern the three types of GP neurons that were described previously in rats (Cooper and Stanford, 2000). We could identify type A neurons by their pacemaker-like spontaneous firing (firing rate $5.2 \pm 1.1 \mathrm{~Hz}, n=9$ cells), high input impedance $(298.2 \pm 34.8 \mathrm{M} \Omega)$, weak hyperpolarizationactivated cation currents $\left(I_{\mathrm{h}}\right)$, and resting membrane potential of $-58.1 \pm 2.2 \mathrm{mV}\left(n=9\right.$ cells) (Fig. $\left.4 A_{2}, A_{3}\right)$. Type B neurons could be identified by their high frequency or burst firing (firing rate $19.9 \pm 5.1 \mathrm{~Hz}, n=23$ cells), low input impedance (91.0 \pm 12.7 M $\Omega$ ), lack of $\mathrm{I}_{\mathrm{h}}$, and low resting membrane potential of $-53.4 \pm 1.3 \mathrm{mV}\left(n=23\right.$ cells) (Fig. $\left.4 A_{2}, A_{3}\right)$. However, some neurons did not meet all criteria for type $B$ neurons, as they either did not fire spontaneously, showed high input impedance (200$300 \mathrm{M} \Omega$ ), or had a slower second component in their spike postphotostimulation. They did not meet all criteria for type C neurons either, so we grouped them together with identified type $\mathrm{B}$ neurons and refer to them collectively as type $\mathrm{B} / \mathrm{C}$ neurons.

Most type A neurons did not show a response to photostimulation (Fig. $4 A_{4}$ ); only 1 of 9 recorded neurons showed a response exceeding the mean +2 SD level of baseline (range 2.8-15.0 pA). The average amplitude of the post-photostimulation epoch in cells without synaptic connections was $4.4 \pm 1.2 \mathrm{pA}$ ( $n=8$ cells $)$ (Fig. $4 \mathrm{~B}$ ), and the amplitude of the IPSC in the one cell showing a significant connection was $8.6 \mathrm{pA}$ (Fig. $4 \mathrm{~B}$ ). In contrast, photostimulation of type $\mathrm{B} / \mathrm{C}$ neurons produced strong responses, with considerable fluctuation in amplitude (Fig. $4 A_{4}$ ). The evoked response was completely blocked by $10 \mu \mathrm{M}$ gabazine (Fig. $\left.4 A_{5}\right)$. Among 23 recorded neurons, 20 (86\%) showed a response larger than the mean +2 SD of the baseline activity (4.1-21.9 pA). The average amplitude of evoked IPSCs in cells with synaptic connections was $65.2 \pm 23.7 \mathrm{pA}(n=20$ cells) (Fig. $4 B)$, while the average amplitude of the post-photostimulation epoch in cells without synaptic connections was $6.8 \pm 3.3 \mathrm{pA}$ ( $n=3$ cells) (Fig. $4 B)$. Thus, MSNs connect preferentially with type B/C neurons.

\section{Connections of MSNs in the SN}

Neurons in the SN are divided into two spatially segregated populations distinguished by their neurotransmitters; neurons in the pars compacta $(\mathrm{SNc})$ are predominantly DAergic, whereas neurons in the pars reticulata $(\mathrm{SNr})$ are predominantly GABAergic (Grace and Onn, 1989; Lacey et al., 1989). SN neurons receive extensive GABAergic input from the Str and the GP, as well as from neighboring SN neurons (Tepper and Lee, 2007), which has made it impossible to study MSN inputs selectively. We were able to do this in BTR:: $\alpha$ CaKII-tTA mice.

SNr GABA neurons fired spontaneously, often in bursts (firing rate $16.4 \pm 3.0 \mathrm{~Hz}, n=22$ cells), had low input impedance $\left(141.7 \pm 13.2 \mathrm{M} \Omega, n=22\right.$ cells), lacked $I_{\mathrm{h}}$ (Fig. $4 C_{2}, C_{3}$ ), and had a resting membrane potential of $-54.7 \pm 1.2 \mathrm{mV}$ ( $n=22$ cells $)$. Photostimulation evoked large inward currents that were completely blocked by gabazine (Fig. $4 C_{4}, C_{5}$ ). Of 22 recorded neurons, 21 (95\%) showed responses larger than mean +2 SD of baseline (4.8-20.9 pA). The average amplitude of evoked IPSCs in cells with synaptic connections was $276.3 \pm 126.1 \mathrm{pA}(n=$ 21 cells) (Fig. 4D), whereas the amplitude of the post- 
photostimulation epoch in the neuron without synaptic connection was $10.7 \mathrm{pA}$ (Fig. 4D).

SNc DA neurons ( $n=17$ cells) were silent or showed slow spontaneous firing $(0.42 \pm 0.42 \mathrm{~Hz})$; they had a high input impedance $\left(268.7 \pm 15.2 \mathrm{M} \Omega\right.$ ), a large $I_{\mathrm{h}}$ (Fig. $4 C_{2}, C_{3}$ ), and a resting membrane potential of $-60.6 \pm 1.8 \mathrm{mV}(n=17$ cells $)$. In striking contrast to $\mathrm{SNr}$ neurons, photostimulation evoked no responses in $\mathrm{SNc}$ neurons (Fig. $4 C_{5}$ ). The average amplitude of the post-photostimulation epoch in all recorded neurons was $2.4 \pm 0.4 \mathrm{pA}$ ( $n=17$ cells) (Fig. $4 D$ ); no neurons showed a response exceeding the mean + $2 \mathrm{SD}$ of the baseline (range, 1.6-5.2 pA). Thus, MSNs appear to connect exclusively with SNr GABA neurons.

Because MSNs in the Str patch compartment have been reported to project to SNc DA neurons (Gerfen, 1985), we could have missed the connections if ChR2expressing MSNs were not in the patch compartment. While this was unlikely given the random scatter of mCherry MSNs in the dorsal Str that we have observed, we addressed this directly by immunostaining for mu opioid receptors, which are a patch marker (Mansour et al., 1995). We found mCherry-expressing ChR2 neurons in both the patch and matrix compartments (supplemental Fig. S4, available at www.jneurosci.org as supplemental material). Therefore, neither patch nor matrix MSNs project to SNc DA neurons.

Analysis of connectivity using $\mathrm{CsCl}$ To assess the connectivity in the MSN projections further, we used a CsCl-based intracellular solution to achieve better space clamp and enhance small or distal inputs. In the GP, MSN inputs impinge on distal dendrites, whereas local inputs impinge on proximal dendrites (Kita, 2007) (Fig. 5, top left schematic). Consistent with this, the light-evoked IPSC in GP neurons measured $140.4 \pm 45.4 \mathrm{pA}(n=$ 19 cells) with $\mathrm{CsCl}$, compared to $65.2 \pm$ $23.7 \mathrm{pA}(n=20$ cells) with $\mathrm{KCl}$ (Fig. 5, bottom left), which was significantly different ( $p=0.042$, unpaired $t$ test). While the $\mathrm{CsCl}$ pipette solution affected firing properties, we could still recognize type $\mathrm{B} / \mathrm{C}$ neurons by their response to photostimulation. Tracer injections have suggested that most Str inputs to $\mathrm{SNr}$ neurons are on their distal dendrites (von Krosigk et al., 1992); we found however that the light-evoked IPSC in SNr neurons was $238.1 \pm 55.9 \mathrm{pA}(n=21$ cells), with $\mathrm{CsCl}$ not differing from the $276.3 \pm 126.1 \mathrm{pA}$ recorded with $\mathrm{KCl}(n=21 ; p=0.84$, unpaired $t$ test) (Fig. 5, center), suggesting that MSN inputs in fact impinge on the more proximal dendrites of $\mathrm{SNr}$ neurons. were seen in SNc neurons.
A1

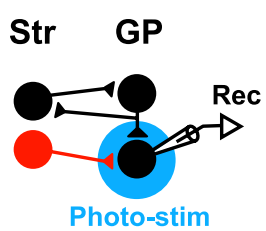

A2
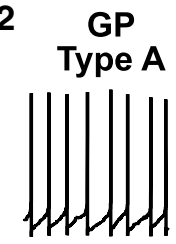

A3

A4

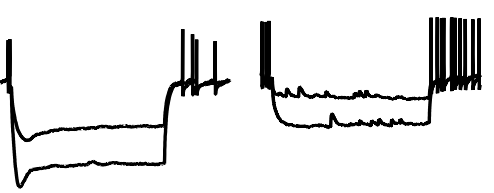

A5
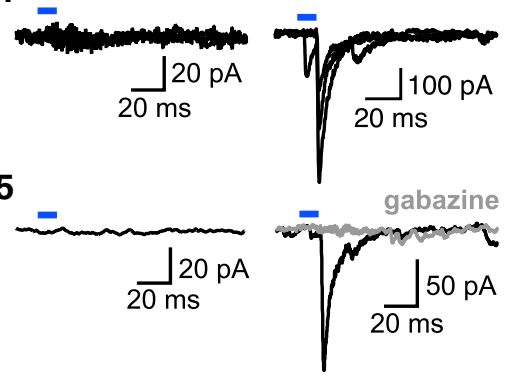

B

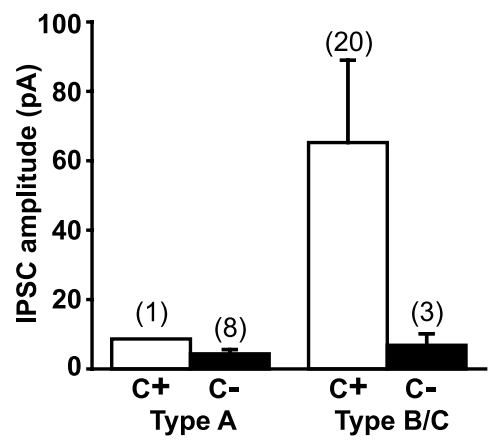
Type B/C

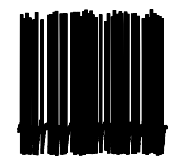

$\mathbf{C}_{1}$

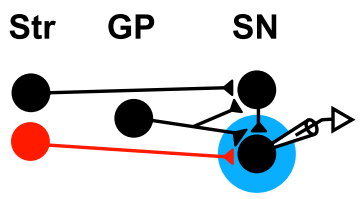

C2

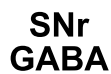

SNC

GABA

DA

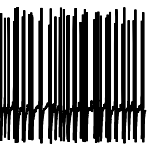

C3
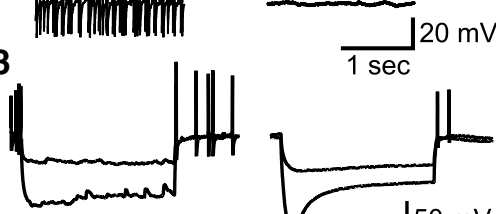

C4

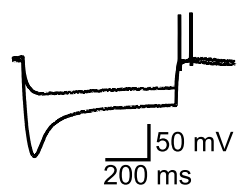

C5

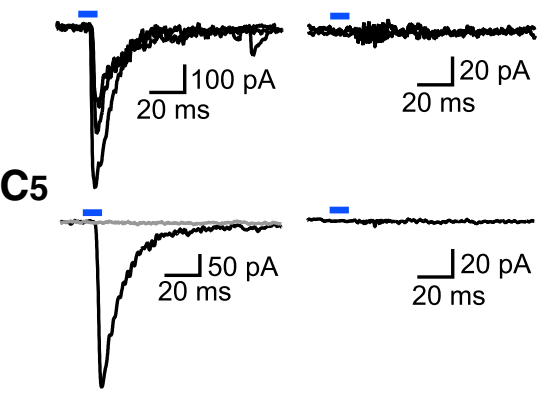

D

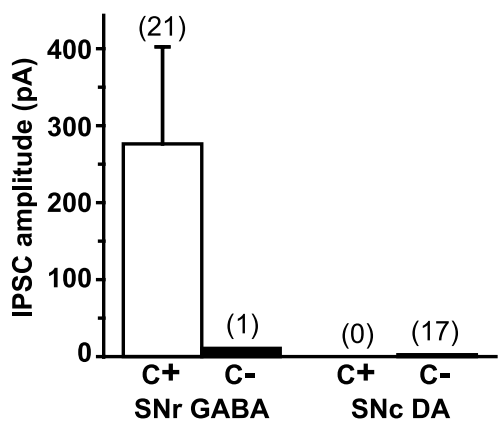

Figure 4. MSN projections in the GP and SN. $\boldsymbol{A}$, Light-evoked IPSCs in the GP. $\boldsymbol{A}_{\boldsymbol{1}}$, Schematic shows GABAergic inputs to the GP. mCherry MSNs are indicated in red; other MSNs and target neurons are indicated in black. $A_{2}, A_{3}$, Target neurons were classified by their spontaneous firing pattern $\left(\boldsymbol{A}_{2}\right)$ and response to hyperpolarizing current injection $\left(\boldsymbol{A}_{3}\right) . \boldsymbol{A}_{4}, \boldsymbol{A}_{5}$, Individual light-evoked IPSCS $\left(\boldsymbol{A}_{4}\right.$, three traces superimposed) and averages of 10 traces $\left(\boldsymbol{A}_{5}\right)$ are shown by cell type. Type $B / C$ neurons in the GP showed light-evoked IPSCS, which were blocked completely by gabazine (10 $\mu \mathrm{M})\left(\boldsymbol{A}_{5}\right.$, gray traces). $\boldsymbol{B}$, Summary of the amplitudes of recorded light-evoked IPSCs in GP cells. Average amplitudes for cells with IPSCS ( $C+$; open bars) and average amplitudes from cells without significant IPSCs ( $C$; closed bars) are shown; the number of cells recorded is shown in parentheses. Light-evoked IPSCS were mainly seen in type B/C cells. $\boldsymbol{C}$, Light-evoked IPSCS in the SN. $\boldsymbol{C}_{\boldsymbol{1}}$, Schematic of the circuitry. $\boldsymbol{C}_{2}, \boldsymbol{C}_{\mathbf{3}}$, SNr GABA and SNc DA neurons were identified by their location (SNr or SNc), spontaneous firing patterns $\left(\boldsymbol{C}_{2}\right)$, and response to hyperpolarization $\left(\boldsymbol{C}_{3}\right)$. $\boldsymbol{C}_{4}$ $\boldsymbol{C}_{5}$, Individual light-evoked IPSCS $\left(\boldsymbol{C}_{4}\right.$, three traces superimposed) and averages of 10 traces $\left(\boldsymbol{C}_{5}\right)$ are shown by cell type. SNr GABA neurons showed light-evoked IPSCS, which were blocked completely by gabazine (10 $\mu \mathrm{m})\left(\boldsymbol{C}_{5}\right.$, gray traces). $\boldsymbol{D}$, Summary of the amplitudes of recorded light-evoked IPSCs in SN cells. Light-evoked IPSC s were seen in all but one SNr GABA neuron, whereas none

We verified the lack of MSN input onto SNc neurons with $\mathrm{CsCl}$ recordings. With $\mathrm{CsCl}$, the average post-photostimulation epoch was $3.90 \pm 0.94 \mathrm{pA}(n=20$ cells $)$, compared to $2.45 \pm 0.42$ pA ( $n=17$ cells $)$ with $\mathrm{KCl}$, which was not significantly different ( $p=0.16$, unpaired $t$ test) (Fig. 5, right) and did not exceed the mean $+2 \mathrm{SD}$ of baseline in either case, further confirming that MSNs do not project to SNc DA neurons. 


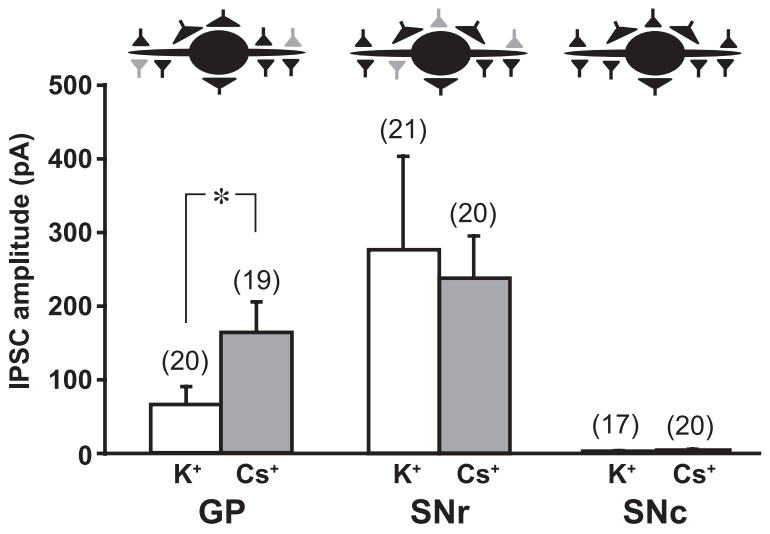

Figure 5. Light-evoked synaptic responses with intracellular $\mathrm{Cs}^{+}$. Schematic diagrams show the putative location of GABAergic synaptic inputs in the GP (left), SNr (middle) and SNc (right), with inputs from mCherry MSNs in gray. The bar graph shows the comparison in the three cell types of light-evoked IPSCs in recordings with $\mathrm{K}^{+}$-based pipette solution (white bars) to recordings with $\mathrm{Cs}^{+}$-based pipette solution (gray bars). The number of cells recorded is shown in parentheses; ${ }^{*} p<0.05$ (unpaired $t$ test). In the GP, $\mathrm{Cs}^{+}$increased IPSC amplitude (left; thus, in the schematic MSN inputs are shown more on distal dendrites). In the $\mathrm{SNr}$, $\mathrm{CS}^{+}$ had no effect on IPSC amplitude (middle; thus, in the schematic MSN inputs are shown on more proximal dendrites). However, in the SNc no light-evoked IPSCS were seen, even with the increased space clamp with Cs ${ }^{+}$(right; thus, in the schematic only black GABAergic inputs are shown).

\section{DA modulation of striatal output in the projection areas}

D1 and D2 receptors are largely segregated in the direct and indirect pathways, so MSN terminals in the two pathways should show differential presynaptic modulation with D1 and D2 agonists. However, in the GP, which is the target of the indirect pathway, in addition to D2-bearing MSN inputs (Gerfen et al., 1990), there are collaterals of the direct pathway (Kawaguchi et al., 1990; Wu et al., 2000) that should bear D1 receptors (Gerfen et al., 1990). If so, MSN terminals in the GP should show both D1 and D2 modulation. To examine presynaptic DA modulation in the target areas, we used intracellular $\mathrm{Cs}^{+}$to improve space clamp (and increase IPSC amplitude) and to reduce postsynaptic DA effects. Intracellular $\mathrm{Cs}^{+}$blocks several voltage-gated $\mathrm{K}^{+}$ channels, including the inward rectifier channels that are the major downstream mediators of D2 receptor activation (Surmeier et al., 2007). We found that the D2 agonist quinpirole ( $2 \mu \mathrm{M})$ inhibited the light-evoked IPSC, which went from $193.1 \pm 49.6 \mathrm{pA}$ to $95.9 \pm 24.5 \mathrm{pA}\left(n=6\right.$ cells) (Fig. $\left.6 A_{3}\right)$, and was reversed by the D2 antagonist sulpiride $(10 \mu \mathrm{M})$ to $179.9 \pm 39.0 \mathrm{pA}(n=6$ cells $)$, while the D1 agonist SKF83822 $(2 \mu \mathrm{M})$ did not have any apparent effect (control, $102.7 \pm 26.8 \mathrm{pA}$ vs SKF83252, $101.2 \pm 27.3 \mathrm{pA}$; $n=6$ cells) (Fig. 6A2). We used the selective DA antagonist to reverse agonist effects quickly. Overall, quinpirole produced a $50 \pm 4 \%$ inhibition $(p<0.0001$, one sample $t$ test), which was fully reversed by sulpiride ( $97 \pm 3 \%)$, whereas SKF83822 ( $2 \mu \mathrm{M})$ had no effect (98 $\pm 5 \%$ ) (Fig. $6 \mathrm{~B}$ ). Thus, the collaterals of direct pathway MSNs do not appear to show D1-mediated-modulation in the GP.

Although we expected that direct pathway MSN input would show D1 modulation (Gerfen et al., 1990), there have been conflicting reports of D1-mediated facilitation (Cameron and Williams, 1993; Radnikow and Misgeld, 1998) and inhibition (Miyazaki and Lacey, 1998). We found that SKF83822 (2 $\mu \mathrm{M})$ enhanced the light-evoked IPSC, which went from $68.3 \pm 32.3$ pA to $123.2 \pm 54.4 \mathrm{pA} ; n=6$ cells) (Fig. $6 C_{2}$ ), and was reversed by the D1 antagonist SCH23390 $(10 \mu \mathrm{M})$ to $60.2 \pm 31.1 \mathrm{pA}(n=6$ cells), whereas the D2 agonist quinpirole did not show any ap-
A1

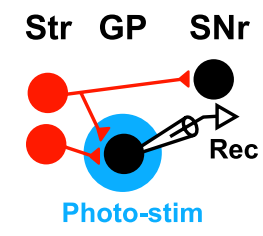

A2

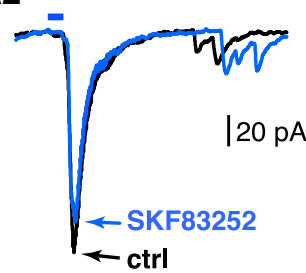

A3

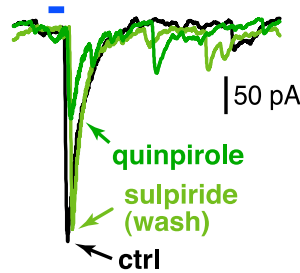

B

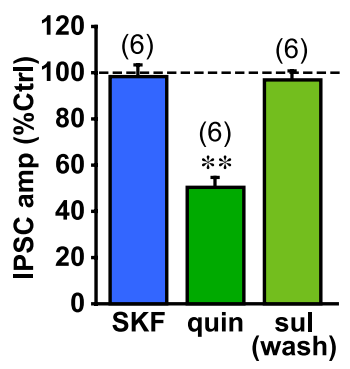

$\mathrm{C}_{1}$

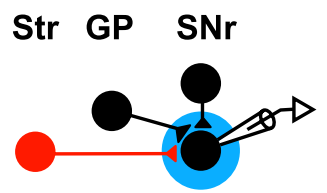

C2

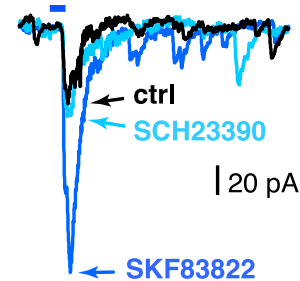

C3

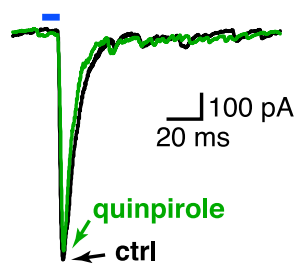

D

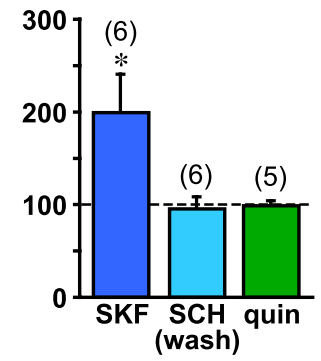

Figure 6. DA modulation of MSN projections. $A_{1}$, Schematic diagram showing indirect pathway MSN projection to the GP (lower red, Str neuron), and direct pathway MSN (upper red, Str neuron) projection through the GP to the SN, with collaterals in the GP. Recordings (Rec) were obtained from putative type $B / C$ GP neurons identified by light-evoked IPSCS, and DA modulation was tested. $A_{2}$, The D1 agonist SKF83822 $(2 \mu \mathrm{M})$ had no effect on the light-evoked IPSC. $A_{3}$, The D2 agonist quinpirole (quin) (2 $\mu \mathrm{M}$ ) inhibited the light-evoked IPSC, which was reversed by the D2 antagonist sulpiride (sul) (10 $\mu \mathrm{M})$. ctrl, Control. B, Summary of effects in the GP for D1 agonist (SKF), D2 agonist (quin), and D2 antagonist (sul) on light-evoked IPSCs expressed as the percentage of the preceding control IPSC amplitude in saline. The dashed line (100\%) indicates no effect. The number of cells recorded is shown in parentheses; ${ }^{* *} p<0.01$ (one-sample $t$ test). $C_{1}$, Schematic shows direct MSN projections to SNr GABA neurons. $C_{2}$, SKF83822 (2 $\left.\mu \mathrm{M}\right)$ facilitated the light-evoked IPSC, which was reversed by the D1 antagonist SCH23390 $(10 \mu \mathrm{M})$. $C_{3}$, The D2 agonist quinpirole had no effect on the light-evoked IPSC. D, Summary of effects in the SNr for D1 agonist (SKF), D1 antagonist (SCH), and D2 agonist (quin); ${ }^{*} p<0.05$.

parent effect (control, $316.7 \pm 195.7 \mathrm{pA}$ vs quinpirole, $131.1 \pm$ $192.1 \mathrm{pA} ; n=5$ cells) (Fig. $6 C_{3}$ ). SKF83822 produced a $200 \pm$ $39 \%$ modulation ( $p=0.039$, one-sample $t$ test), which was fully reversed by SCH23390 (96 $\pm 15 \%)$, whereas quinpirole had no effect $(99 \pm 5 \%$ ) (Fig. $6 D$ ). Thus, MSN inputs onto SNr neurons show D1-mediated facilitation exclusively.

\section{Discussion}

We have resolved long-standing issues in the functional connectivity of MSNs using the first line of transgenic mice expressing ChR2 in a defined cell population. Photostimulation of MSN presynaptic terminals expressing ChR2 elicits $\mathrm{GABA}_{\mathrm{A}}$ synaptic responses from local collaterals in the dorsal Str, as well as in their 


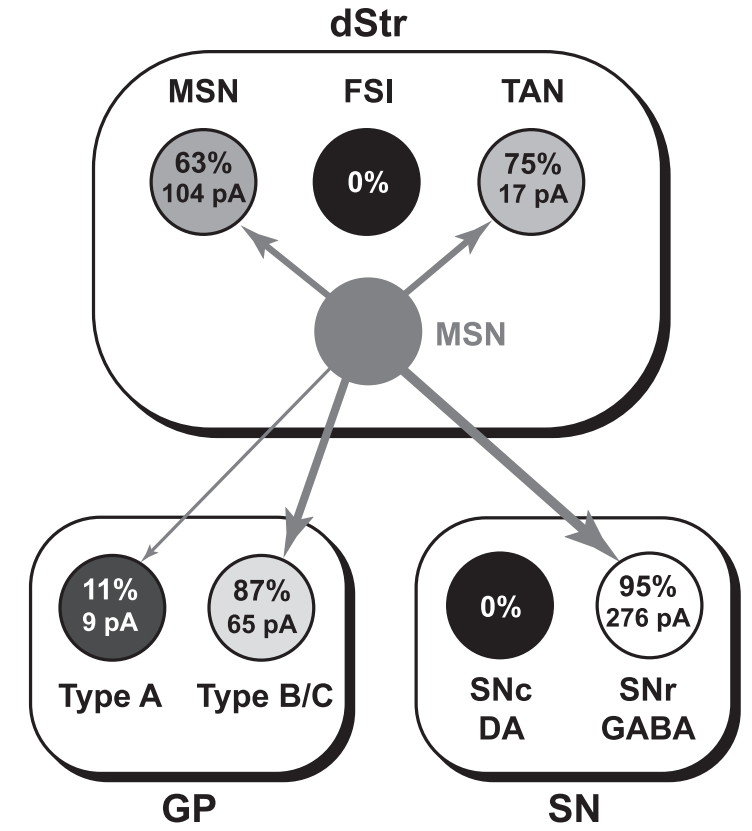

Figure 7. MSN functional connectome. Identified neuron populations are shown as circles within outlines indicating the $\mathrm{dStr}, \mathrm{GP}$, and SN. mCherry MSNs expressing ChR2 are shown in the center (solid gray circle without text). Connections to target neurons are shown as gray arrows. The relative strengths of the connections are indicated by the thickness of the arrows and tone of gray (black for $0 \%$ and white for $100 \%$ ) of circles showing postsynaptic neuron types; arrows were not drawn if there were no connections. In each cell, the top number indicates the percentage of target neurons showing detectable light-evoked IPSCS, and the bottom number indicates the average amplitude of the IPSCs. For example, in the dStr 63\% of non-mCherry MSNs showed significant light-evoked synaptic responses (of average amplitude $104 \mathrm{pA}$ ), no FSIs showed responses, and 75\% of TANs showed responses (of average amplitude $17 \mathrm{pA}$ ). Because only $\sim 10 \%$ of MSNs expressed ChR2 in BTR:: $\alpha$ CaMKII-tTA bigenic mice, the amplitudes shown should be scaled about tenfold to obtain the actual strength of the connections.

projections to the GP and SN. In BTR:: $\alpha$ CaKII-tTA mice, the expression and distribution of ChR2-mCherry cells was consistent from animal to animal so we could compare the specificity and strength of MSN connections. We found that MSN synaptic connections are quite specific (Fig. 7). In the dorsal Str (dStr), MSNs connect robustly to other MSNs and less robustly to TANs, but not to FSIs. In the GP, MSNs connect strongly to type B/C neurons and practically not to type A neurons. In the SN, MSNs make their strongest connections with $\mathrm{SNr}$ GABAergic neurons, but no connections with SNc DA neurons. This transgenic ChR2 strategy provides definitive information on both the specificity and strength of MSN connections.

Differential ChR2 expression among subsets of MSNs appears to be an unlikely explanation for the connectivity data obtained. Whereas $<10 \%$ of MSNs in the dStr of BTR:: $\alpha$ CaMKII-tTA mice express ChR2, both direct and indirect pathway MSNs express ChR2 robustly, arguing against differential expression between the two major classes of MSNs. Moreover, both patch and matrix MSNs express ChR2. ChR2 expression in MSNs appears to follow a Golgi-stain like pattern, arguing that ChR2-expressing neurons are representative of the entire population of MSNs in the dStr. The implication is that while the specificity in connectivity we have observed should be accurate, the strength of the connections we have observed should be scaled about tenfold to obtain the actual strength of the connections.

Before the advent of optogenetics, paired recordings were the only way to assess functional connectivity between identified neurons, but this was limited to neighboring neurons or to syn- apses with large presynaptic terminals. Evidently, paired recordings are not suited to the MSN projections because of physical distance. In the Str, paired recordings only relatively recently demonstrated functional connections between MSNs (Tepper et al., 2004). While paired recordings provide information on connections between single cell pairs, the transgenic ChR2 approach provides access to the sum total of the input from a given cell population converging on a single identified neuron and, moreover, in a single experiment. Thus, it provides a far more robust and efficient way to assess functional connectivity.

Reflecting the difference between single and mass inputs, the incidence of MSN-MSN synaptic connections with our transgenic ChR2 approach (63\%) was significantly greater than that reported in paired recordings $(10-37 \%)$ (Tunstall et al., 2002; Venance et al., 2004; Taverna et al., 2008; Tecuapetla et al., 2009). In contrast to the divergent connectivity of FSIs, MSNs appear to show convergent connectivity, so that individual connections are quite weak. However, when the aggregate of MSN inputs onto a given MSN is considered, as we have assessed in our transgenic ChR2 approach and scaled tenfold (to take into account the $10 \%$ ChR2 expression frequency), MSN connections should be comparable in strength to FSI connections, highlighting their significance. In the Str slice, MSNs form cell assemblies that encode the storage and retrieval of memories (Carrillo-Reid et al., 2008). Mimicking Parkinson's disease, changes in MSN-MSN connections in DA-depleted mice give rise to altered transitions between cell assemblies that are likely to underlie pathological Str output (Jaidar et al., 2010). Based on the strength and numbers of MSNMSN connections, it is likely that Str cell assemblies are determined in a significant part by MSN-MSN connections.

What we have found regarding the connectivity of MSNs to TANs and not to FSIs confirms results in previous paired recordings (Koos and Tepper, 1999; Taverna et al., 2007; Sullivan et al., 2008), but provides new information on the relative strength of the connections. It is known that TANs become silent during pavlovian conditioning (Aosaki et al., 1994), which could be mediated by MSN inputs. The lack of connections from MSNs to FSIs confirms the feedforward inhibitory role of the FSIs in Str information processing. Without cell-specific markers, we could not identify smaller subsets of interneurons. Some of these nonrecorded interneuron subsets do receive input from MSNs, such as the very small number of tyrosine hydroxylase-positive Str interneurons (Ibanez-Sandoval et al., 2010); however, given their very small numbers, it is unlikely that these neurons would have biased the connectivity we determined in the Str.

In the GP, Cooper and Stanford (2000) identified three types of neurons based solely on electrophysiological properties, unsupported by other parameters such as neurotransmitter status or connectivity. Recently, the argument has been made that the different neuron types reflect different activity states of a single population of neurons (Günay et al., 2008), indicative of longstanding issues in the classification of neurons based solely on their electrophysiological properties (Kita, 2007). The clear difference in connectivity we observed between type $\mathrm{A}$ and $\mathrm{B} / \mathrm{C}$ neurons supports the electrophysiological classification; it does not, however, rule out the possibility that during development differences in connectivity engender the differences in the firing properties of the two types of neurons.

In the $\mathrm{SN}$, we observed that MSN input was exclusively onto SNr GABAergic neurons, even when space clamp was increased with intracellular $\mathrm{Cs}^{+}$. Because the majority of SNc-projecting MSNs are in the Str patch compartment (Gerfen, 1985), we could have obtained this result if there were no ChR2-expressing MSNs 
in the patch compartment. However, we found ChR2-expressing MSNs in patches (identified by mu opioid receptor staining). Based on the evident ability of this transgenic ChR2 approach to bring out connections where they were hard to find, i.e., among MSNs, direct MSN input to DA neurons seems improbable. If such connections do exist, they must be quite weak to have eluded detection and thus would have little functional impact. We conclude that MSNs do not influence SNc DA neurons directly, at least under normal conditions. The possibility remains that the direct MSN connections to DA neurons become prominent in pathological conditions. Our observation contradicts a previous report that striatal stimulation inhibits DA neuron activity (Paladini et al., 1999); however, electrical stimulation is not as selective as optogenetic activation.

Of all the MSN connections, projections onto $\mathrm{SNr}$ neurons were by far the strongest. The specificity of MSN connections onto SNr GABA neurons and the anatomical location of Str projection fibers, which run parallel to the medial forebrain bundle (MFB), together explain the striking effects of MFB selfstimulation (Bielajew and Harris, 1991). MFB stimulation activates Str output fibers that would inhibit SNr GABA neurons, removing their strong inhibition of DA neurons, which would then burst fire (Tepper and Lee, 2007). Thus, MFB stimulation should synergistically activate DA neurons by direct stimulation of their axons, activation of glutamatergic afferents, and inhibition of their principal inhibitory inputs.

Although the expression of D1 and D2 receptors in direct and indirect pathway MSNs is strictly segregated (Gerfen et al., 1990), the question remains as to whether there is such a distinct functional segregation in both MSN-MSN connections and in the projections of the neurons. While optogenetic assessment of the pharmacology of MSN-MSN connections must await future experiments with selective expression of ChR2 in the two subpopulations of MSNs, we addressed this issue in the projections and found evidence for strict segregation. This is despite the fact that direct pathway MSNs have axon collaterals in the GP (Kawaguchi et al., 1990; Wu et al., 2000); if D1 receptors are expressed on all the terminals of direct pathway MSNs, then the collaterals in the GP should show D1 modulation. We did not, however, observe any D1 effect on MSN inputs in the GP. As suggested some time ago (Surmeier et al., 1993) and reinforced by more recent studies (Mizuno et al., 2007), MSNs appear to traffic DA receptors differentially to subsets of their presynaptic terminals.

We observed D1-mediated facilitation of MSN projections in the $\mathrm{SNr}$, as was originally reported in the ventral tegmental area (Cameron and Williams, 1993) and in the SNr (Radnikow and Misgeld, 1998). The report of D1-mediated inhibition (Miyazaki and Lacey, 1998) could be due to differences in the afferents stimulated, or reflect the contribution of postsynaptic D1 modulation. Recent single-cell gene expression analyses show that SNr neurons express both D1 and D5 receptors (Zhou et al., 2009), so it remains possible that direct pathway input is differentially modulated presynaptically and postsynaptically.

As exemplified in the present studies with transgenic expression of ChR2 in MSNs, the specificity and strength of synaptic connections made by genetically defined neuron populations can now be determined. By sampling the synaptic actions of a defined cell population, a far greater sensitivity and reliability in the determination becomes possible. With other cell type-specific promoters, this approach should provide the means to determine the functional connectome of any given population of neurons, how the connectome is modulated, and how the connectome changes during maturation as a consequence of experience or with pathological processes.

\section{References}

Aosaki T, Tsubokawa H, Ishida A, Watanabe K, Graybiel AM, Kimura M (1994) Responses of tonically active neurons in the primate's striatum undergo systematic changes during behavioral sensorimotor conditioning. J Neurosci 14:3969-3984.

Arenkiel BR, Peca J, Davison IG, Feliciano C, Deisseroth K, Augustine GJ, Ehlers MD, Feng G (2007) In vivo light-induced activation of neural circuitry in transgenic mice expressing channelrhodopsin-2. Neuron 54:205-218.

Bamberg E, Bamann C, Feldbauer K, Kleinlogel S, Spitz J, Zimmermann D, Wood P, Nagel G (2008) Channelrhodopsins: molecular properties and applications. In: Optical control of neural excitability (Keshishian H, ed), pp 13-20. Washington, DC: Society for Neuroscience.

Bielajew CH, Harris T (1991) Self-stimulation: a rewarding decade. J Psychiatry Neurosci 16:109-114.

Bohland JW, Wu C, Barbas H, Bokil H, Bota M, Breiter HC, Cline HT, Doyle JC, Freed PJ, Greenspan RJ, Haber SN, Hawrylycz M, Herrera DG, Hilgetag CC, Huang ZJ, Jones A, Jones EG, Karten HJ, Kleinfeld D, Kötter $\mathrm{R}$, et al. (2009) A proposal for a coordinated effort for the determination of brainwide neuroanatomical connectivity in model organisms at a mesoscopic scale. PLoS Comput Biol 5:e1000334.

Boyden ES, Zhang F, Bamberg E, Nagel G, Deisseroth K (2005) Millisecondtimescale, genetically targeted optical control of neural activity. Nat Neurosci 8:1263-1268.

Cameron DL, Williams JT (1993) Dopamine D1 receptors facilitate transmitter release. Nature 366:344-347.

Carrillo-Reid L, Tecuapetla F, Tapia D, Hernández-Cruz A, Galarraga E, Drucker-Colin R, Bargas J (2008) Encoding network states by striatal cell assemblies. J Neurophysiol 99:1435-1450.

Cooper AJ, Stanford IM (2000) Electrophysiological and morphological characteristics of three subtypes of rat globus pallidus neurone in vitro. J Physiol 527:291-304.

Drew MR, Simpson EH, Kellendonk C, Herzberg WG, Lipatova O, Fairhurst S, Kandel ER, Malapani C, Balsam PD (2007) Transient overexpression of striatal D2 receptors impairs operant motivation and interval timing. J Neurosci 27:7731-7739.

Falls WM, Park MR, Kitai ST (1983) An intracellular HRP study of the rat globus pallidus. II. Fine structural characteristics and synaptic connections of medially located large GP neurons. J Comp Neurol 221:229-245.

Gerfen CR (1985) The neostriatal mosaic. I. Compartmental organization of projections from the striatum to the substantia nigra in the rat. J Comp Neurol 236:454-476.

Gerfen CR, Engber TM, Mahan LC, Susel Z, Chase TN, Monsma FJ Jr, Sibley DR (1990) D1 and D2 dopamine receptor-regulated gene expression of striatonigral and striatopallidal neurons. Science 250:1429-1432.

Gossen M, Freundlieb S, Bender G, Müller G, Hillen W, Bujard H (1995) Transcriptional activation by tetracyclines in mammalian cells. Science 268:1766-1769.

Grace AA, Onn SP (1989) Morphology and electrophysiological properties of immunocytochemically identified rat dopamine neurons recorded in vitro. J Neurosci 9:3463-3481.

Graybiel AM (2000) The basal ganglia. Curr Biol 10:R509-R511.

Graybiel AM, Aosaki T, Flaherty AW, Kimura M (1994) The basal ganglia and adaptive motor control. Science 265:1826-1831.

Günay C, Edgerton JR, Jaeger D (2008) Channel density distributions explain spiking variability in the globus pallidus: a combined physiology and computer simulation database approach. J Neurosci 28:7476-7491.

Guzmán JN, Hernández A, Galarraga E, Tapia D, Laville A, Vergara R, Aceves J, Bargas J (2003) Dopaminergic modulation of axon collaterals interconnecting spiny neurons of the rat striatum. J Neurosci 23:8931-8940.

Ibáñez-Sandoval O, Tecuapetla F, Unal B, Shah F, Koós T, Tepper JM (2010) Electrophysiological and morphological characteristics and synaptic connectivity of tyrosine hydroxylase-expressing neurons in adult mouse striatum. J Neurosci 30:6999-7016.

Jáidar O, Carrillo-Reid L, Hernández A, Drucker-Colín R, Bargas J, Hernández-Cruz A (2010) Dynamics of the parkinsonian striatal microcircuit: entrainment into a dominant network state. J Neurosci 30:11326-11336.

Kawaguchi Y (1993) Physiological, morphological, and histochemical char- 
acterization of three classes of interneurons in rat neostriatum. J Neurosci 13:4908-4923.

Kawaguchi Y, Wilson CJ, Emson PC (1990) Projection subtypes of rat neostriatal matrix cells revealed by intracellular injection of biocytin. J Neurosci 10:3421-3438.

Kawaguchi Y, Wilson CJ, Augood SJ, Emson PC (1995) Striatal interneurones: chemical, physiological and morphological characterization. Trends Neurosci 18:527-535.

Kellendonk C, Simpson EH, Polan HJ, Malleret G, Vronskaya S, Winiger V, Moore H, Kandel ER (2006) Transient and selective overexpression of dopamine $\mathrm{D} 2$ receptors in the striatum causes persistent abnormalities in prefrontal cortex functioning. Neuron 49:603-615.

Kita H (2007) Globus pallidus external segment. Prog Brain Res 160:111-133.

Kita H, Kitai ST (1994) The morphology of globus pallidus projection neurons in the rat: an intracellular staining study. Brain Res 636:308-319.

Koós T, Tepper JM (1999) Inhibitory control of neostriatal projection neurons by GABAergic interneurons. Nat Neurosci 2:467-472.

Kreitzer AC, Malenka RC (2008) Striatal Plasticity and Basal Ganglia Circuit Function. Neuron 60:543-554.

Kuhlman SJ, Huang ZJ (2008) High-resolution labeling and functional manipulation of specific neuron types in mouse brain by Cre-activated viral gene expression. PLoS One 3:e2005.

Lacey MG, Mercuri NB, North RA (1989) Two cell types in rat substantia nigra zona compacta distinguished by membrane properties and the actions of dopamine and opioids. J Neurosci 9:1233-1241.

Mansour A, Fox CA, Burke S, Akil H, Watson SJ (1995) Immunohistochemical localization of the cloned mu opioid receptor in the rat CNS. J Chem Neuroanat 8:283-305.

Mayford M, Bach ME, Huang YY, Wang L, Hawkins RD, Kandel ER (1996) Control of memory formation through regulated expression of a CaMKII transgene. Science 274:1678-1683.

Miyazaki T, Lacey MG (1998) Presynaptic inhibition by dopamine of a discrete component of GABA release in rat substantia nigra pars reticulata. J Physiol 513:805-817.

Mizuno T, Schmauss C, Rayport S (2007) Distinct roles of presynaptic dopamine receptors in the differential modulation of the intrinsic synapses of medium-spiny neurons in the nucleus accumbens. BMC Neurosci 8:8.

Okoyama S, Nakamura Y, Moriizumi T, Kitao Y (1987) Electron microscopic analysis of the synaptic organization of the globus pallidus in the cat. J Comp Neurol 265:323-331.

Paladini CA, Celada P, Tepper JM (1999) Striatal, pallidal, and pars reticulata evoked inhibition of nigrostriatal dopaminergic neurons is mediated by GABA(A) receptors in vivo. Neuroscience 89:799-812.

Radnikow G, Misgeld U (1998) Dopamine D1 receptors facilitate $G_{A B A}$ synaptic currents in the rat substantia nigra pars reticulata. J Neurosci 18:2009-2016.

Robbins TW, Ersche KD, Everitt BJ (2008) Drug addiction and the memory systems of the brain. Ann NY Acad Sci 1141:1-21.
Simpson EH, Kellendonk C, Kandel E (2010) A possible role for the striatum in the pathogenesis of the cognitive symptoms of schizophrenia. Neuron 65:585-596.

Sullivan MA, Chen H, Morikawa H (2008) Recurrent inhibitory network among striatal cholinergic interneurons. J Neurosci 28:8682-8690.

Surmeier DJ, Reiner A, Levine MS, Ariano MA (1993) Are neostriatal dopamine receptors co-localized? Trends Neurosci 16:299-305.

Surmeier DJ, Ding J, Day M, Wang Z, Shen W (2007) D1 and D2 dopaminereceptor modulation of striatal glutamatergic signaling in striatal medium spiny neurons. Trends Neurosci 30:228-235.

Taverna S, Canciani B, Pennartz CM (2007) Membrane properties and synaptic connectivity of fast-spiking interneurons in rat ventral striatum. Brain Res 1152:49-56.

Taverna S, Ilijic E, Surmeier DJ (2008) Recurrent collateral connections of striatal medium spiny neurons are disrupted in models of Parkinson's disease. J Neurosci 28:5504-5512.

Tecuapetla F, Koós T, Tepper JM, Kabbani N, Yeckel MF (2009) Differential dopaminergic modulation of neostriatal synaptic connections of striatopallidal axon collaterals. J Neurosci 29:8977-8990.

Tepper JM, Lee CR (2007) GABAergic control of substantia nigra dopaminergic neurons. Prog Brain Res 160:189-208.

Tepper JM, Koós T, Wilson CJ (2004) GABAergic microcircuits in the neostriatum. Trends Neurosci 27:662-669.

Tsai HC, Zhang F, Adamantidis A, Stuber GD, Bonci A, de Lecea L, Deisseroth $\mathrm{K}$ (2009) Phasic firing in dopaminergic neurons is sufficient for behavioral conditioning. Science 324:1080-1084.

Tunstall MJ, Oorschot DE, Kean A, Wickens JR (2002) Inhibitory interactions between spiny projection neurons in the rat striatum. J Neurophysiol 88:1263-1269.

Venance L, Glowinski J, Giaume C (2004) Electrical and chemical transmission between striatal GABAergic output neurones in rat brain slices. J Physiol 559:215-230.

von Krosigk M, Smith Y, Bolam JP, Smith AD (1992) Synaptic organization of GABAergic inputs from the striatum and the globus pallidus onto neurons in the substantia nigra and retrorubral field which project to the medullary reticular formation. Neuroscience 50:531-549.

Wilson CJ (2004) The basal ganglia. In: The synaptic organization of the brain, Ed 5 (Shepherd GM, ed), pp 361-413. Oxford: Oxford UP.

Wu Y, Richard S, Parent A (2000) The organization of the striatal output system: a single-cell juxtacellular labeling study in the rat. Neurosci Res $38: 49-62$.

Yin HH, Knowlton BJ (2006) The role of the basal ganglia in habit formation. at Rev Neurosci 7:464-476.

Zhang F, Wang LP, Boyden ES, Deisseroth K (2006) Channelrhodopsin-2 and optical control of excitable cells. Nat Methods 3:785-792.

Zhou FW, Jin Y, Matta SG, Xu M, Zhou FM (2009) An ultra-short Dopamine pathway regulates basal ganglia output. J Neurosci 29:10424-10435 